\title{
Frações granulométricas da matéria orgânica do solo em consórcio de milho safrinha com capim-marandu sob fontes de nitrogênio
}

\author{
Fabiane Cargnin Faccin ${ }^{(1)}$, Marlene Estevão Marchetti( ${ }^{(1)}$, Ademar Pereira Serra ${ }^{(2)}$ e Simone Cândido Ensinas(3) \\ (1)Universidade Federal da Grande Dourados, Faculdade de Agronomia, Rodovia Dourados-Itahum, Km 12, Cidade Universitária, Caixa \\ Postal 533, CEP 79804-970 Dourados, MS, Brasil. E-mail: fabiane_faccin@hotmail.com, marlenemarchetti@ufgd.edu.br(2)Embrapa \\ Gado de Corte, Avenida Rádio Maia, no 830, Zona Rural, CEP 79106-550 Campo Grande, MS, Brasil. E-mail: ademar.serra@embrapa.br \\ (3)Universidade Estadual de Mato Grosso do Sul, Unidade Universitária de Cassilândia, Departamento de Agronomia, MS 306, Km 6,4, \\ CEP 79540-000 Cassilândia, MS, Brasil. E-mail: simone_candido@hotmail.com
}

Resumo - O objetivo deste trabalho foi determinar o efeito do consórcio de milho safrinha com Urochloa brizantha 'Marandu' e de fontes de nitrogênio nas frações granulométricas da matéria orgânica do solo em sistema plantio direto. Os tratamentos foram dispostos em arranjo fatorial $2 \times 4$ - dois tipos de cultivo de milho (com ou sem pasto) e quatro fontes de nitrogênio (sem nitrogênio, ureia, sulfato de amônio+ureia e sulfato de amônio) -, em blocos ao acaso, com quatro repetições. O experimento foi conduzido de 2005 a 2013. As coletas do solo foram realizadas em 2013, após a colheita do milho no outono/inverno, em quatro profundidades: $0-5,5-10,10-20$ e $20-40 \mathrm{~cm}$. Foram determinados os teores de carbono orgânico total (COT), lábil (CL), particulado (COP) e mineral (COM). O consórcio de milho com U. brizantha 'Marandu' resulta em maior teor de COT, CL e COP do que o cultivo de milho solteiro no outono/inverno. O sulfato de amônio+ureia aumenta os teores de COT na camada de 0-5 cm, mas os diminui na de 20-40 cm, além de incrementar os teores de COM em todas as profundidades. Os maiores teores de carbono orgânico total, lábil e particulado são verificados nas profundidades de $0-5$ e $5-10 \mathrm{~cm}$.

Termos para indexação: Zea mays, fracionamento físico, matéria orgânica leve, plantio direto.

\section{Granulometric fractions of soil organic matter in intercropping of off-season corn with Marandu grass under nitrogen sources}

\begin{abstract}
The objective of this work was to determine the effect of off-season corn intercropped with Urochloa brizantha 'Marandu' and of nitrogen sources on the granulometric fractions of soil organic matter under a notillage system. The treatments were arranged in a $2 \times 4$ factorial arrangement - two types of corn cultivation (with or without pasture) and four nitrogen sources (without nitrogen, urea, ammonium sulfate+urea, and ammonium sulfate) -, in randomized complete blocks with four replicates. The experiment was carried out from 2005 to 2013. Soil sampling was performed in 2013, after corn harvest in fall/winter, at four depths: $0-5$, 5-10, 10-20, and 20-40 cm. Total (TOC), labile (LC), particulate (POC), and mineral-associated organic carbon (MOC) contents were determined. The intercropping of corn with $U$. brizantha 'Marandu' results in a higher concentration of TOC, LC, and POC than single corn cultivated in fall/winter. Ammonium sulfate+urea increases TOC contents at the $0-5-\mathrm{cm}$ depth, but decreases them at the $20-40-\mathrm{cm}$ depth, besides increasing the MOC contents at all depths. The highest total, labile, and particulate organic carbon contents are observed at the $0-5$ and $5-10-\mathrm{cm}$ depths.
\end{abstract}

Index terms: Zea mays, physical fractionation, light organic matter, no-tillage.

\section{Introdução}

A região do Cerrado destaca-se no cenário agrícola nacional devido, principalmente, ao relevo e às propriedades físicas dos solos (Siqueira Neto et al., 2009). No Estado do Mato Grosso do Sul, o cultivo em sucessão de soja e milho de segunda safra tem ocupado grandes áreas, com 1.668.256 ha (Levantamento..., 2016) e relevante impacto sobre o agronegócio brasileiro.
Nas áreas cultivadas com a sucessão soja/milho, tem-se adotado o sistema plantio direto, o que incrementa os teores de matéria orgânica e melhora os atributos químicos, físicos e biológicos do solo (Guedes et al., 2012; Ensinas et al., 2015; Rosa et al., 2015; Lourente et al., 2016). Entretanto, apesar de a soja ser uma cultura com boa adaptação em sistema plantio direto, os sojicultores têm encontrado dificuldades na 
obtenção e na manutenção da cobertura de matéria orgânica do solo (MOS) (Freitas et al., 2016; Souza et al., 2016).

A utilização do consórcio de milho safrinha com Urochloa spp. (Syn. Brachiaria spp.) é uma alternativa que vem se mostrando viável para o incremento e a manutenção da matéria orgânica sobre o solo em sistema plantio direto (Ensinas et al., 2015; Freitas et al., 2016). Nesse consórcio, o milho é utilizado como cultura econômica e Urochloa spp. como cultura de cobertura, para incrementar a produção de biomassa sobre o solo, o que favorece as culturas subsequentes (Crusciol et al., 2010; Borghi et al., 2013) e possibilita a semeadura da soja após a dessecação da espécie forragem (Ceccon, 2007).

A permanência da matéria orgânica no solo está relacionada a fatores de manejo, com destaque para a adubação nitrogenada em cobertura, que pode aumentar a taxa de decomposição do resíduo sobre o solo (Potrich et al., 2014). Na cultura do milho, a adubação nitrogenada em cobertura é realizada de forma rotineira para obter produtividades economicamente viáveis (Souza et al., 2016). Contudo, as fontes de nitrogênio podem alterar a produção e a taxa de decomposição da matéria orgânica, o que torna primordial o conhecimento desses efeitos nas frações granulométricas da MOS.

A rápida decomposição da matéria orgânica é explicada pela baixa relação $\mathrm{C} / \mathrm{N}$ das culturas antecessoras à soja, o que leva à uma rápida decomposição dos resíduos vegetais, e pela baixa produção de massa seca de algumas espécies. Neste contexto, o consórcio de milho com Urochloa spp. tem sido utilizado para aumentar a oferta de resíduos culturais e promover benefícios às culturas subsequentes (Crusciol et al., 2010; Borghi et al., 2013).

O consórcio entre culturas, portanto, permite aumentar a sustentabilidade de sistemas produtivos (Hu et al., 2016), por meio do aumento do carbono no solo (Ensinas et al., 2016) e, também, da agregação de valores com duas culturas na mesma área (Crusciol et al., 2010). Quanto à agricultura de baixo carbono, sistemas de produção que contribuem para o incremento do sequestro de carbono no solo vêm sendo incentivados, como os sistemas integrados de produção associados ao plantio direto, por serem uma estratégia eficiente que pode reduzir em até $16 \%$ a emissão de $\mathrm{CO}_{2}$ equivalente (Hu et al., 2016).
Embora haja muita pesquisa sobre sistemas consorciados, ainda persistem questionamentos em relação ao aumento do carbono orgânico no solo e ao fracionamento da matéria orgânica. Em sistema plantio direto, a alteração no carbono orgânico total pode ser pouco perceptiva nos primeiros anos de cultivo (Lourente et al., 2016). Entretanto, em sistemas de consórcio milho safrinha com capimmarandu, em três anos de cultivo, foram observados teores de carbono mais elevados que em áreas de vegetação nativa de cerrado (Ensinas et al., 2016). Isso é indicativo de que são necessários mais estudos para um melhor entendimento da relação do manejo de sistemas de produção em consórcio com as fontes de fertilizantes nitrogenados e os seus efeitos no fracionamento da MOS.

O objetivo deste trabalho foi determinar o efeito do consórcio de milho safrinha com $U$. brizantha 'Marandu' e de fontes de nitrogênio nas frações granulométricas da MOS em sistema plantio direto.

\section{Material e Métodos}

O trabalho foi conduzido no período de 2005 a 2013, no Município de Maracaju, MS (2138'17"S, 559'14"W, a $405 \mathrm{~m}$ de altitude). $\mathrm{O}$ solo da área experimental foi classificado como Latossolo Vermelho distroférrico textura argilosa (Santos et al., 2013). O clima da região, de acordo com a classificação de Köppen, é do tipo Aw, tropical úmido, com chuvas no verão e seca no inverno, com temperatura média anual de $27^{\circ} \mathrm{C}$ e precipitação média anual de 1.500 a $1.750 \mathrm{~mm}$.

O experimento foi iniciado no outono/inverno de 2005 e finalizado no outono/inverno de 2013 , o que totalizou nove cultivos de milho segunda safra (milho safrinha) (Zea mays L.) e oito cultivos de soja [Glycine $\max ($ L.) Merr.]. Para a caracterização do solo, foram analisados alguns atributos químicos e físicos iniciais na profundidade de $0-20 \mathrm{~cm}$, de acordo com Claessen (1997): $\mathrm{pH}\left(\mathrm{CaCl}_{2}\right) 5,05 ; 34,20 \mathrm{~g} \mathrm{dm}^{-3}$ de MOS; 31,49 $\mathrm{mg} \mathrm{dm}{ }^{-3}$ de P; $0,79 \mathrm{cmol}_{\mathrm{c}} \mathrm{dm}^{-3}$ de K $\mathrm{K}^{+} ; 3,90 \mathrm{cmol}_{\mathrm{c}} \mathrm{dm}^{-3} \mathrm{de}$

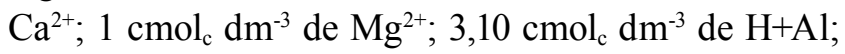
$0 \mathrm{cmol}_{\mathrm{c}} \mathrm{dm}^{-3}$ de $\mathrm{Al}^{3+}$; soma de base de 5,69 $\mathrm{cmol}_{\mathrm{c}} \mathrm{dm}^{-3}$; capacidade de troca de cátions de $10,23 \mathrm{cmol}_{\mathrm{c}} \mathrm{dm}^{-3}$; saturação por base de $56,15 \% ; 390 \mathrm{~g} \mathrm{~kg}^{-1}$ de argila; $310 \mathrm{~g} \mathrm{~kg}^{-1}$ de areia; e $300 \mathrm{~g} \mathrm{~kg}^{-1}$ de silte. Com base no resultado da análise química do solo, em 2005, antes da semeadura do milho, foram aplicados $2 \mathrm{Mg} \mathrm{ha}^{-1} \mathrm{de}$

Pesq. agropec. bras., Brasília, v.51, n.12, p.2000-2009, dez. 2016 DOI: 10.1590/S0100-204X2016001200011 
calcário dolomítico (PRNT $=75 \%, 33 \%$ de $\mathrm{CaO}$ e $15 \%$ de $\mathrm{MgO}$ ) e $500 \mathrm{~kg} \mathrm{ha}^{-1}$ de gesso agrícola. A calagem e a gessagem foram realizadas a lanço, sem incorporação.

$\mathrm{O}$ experimento foi instalado em delineamento experimental de blocos ao acaso, com quatro repetições, em arranjo fatorial $2 \times 4$, o que totalizou oito tratamentos (Tabela 1). Foram avaliados dois tipos de cultivo de milho - consórcio de milho com U. brizantha 'Marandu' ou milho sem consórcio (milho solteiro) -, e quatro fontes de adubo nitrogenado - sem nitrogênio, ureia, sulfato de amônio+ureia e sulfato de amônio. As parcelas experimentais apresentaram dimensão de $5 \mathrm{~m}$ de largura por $12 \mathrm{~m}$ de comprimento, o que totalizou $60 \mathrm{~m}^{2}$ de área cultivada. Para a formação do consórcio de milho com $U$. brizantha 'Marandu', foram semeados 2,5 $\mathrm{kg} \mathrm{ha}^{-1}$ de sementes puras e viáveis de $U$. brizantha 'Marandu', no espaçamento de $20 \mathrm{~cm}$, com auxílio de semeadora automotriz; em seguida, foi realizada a semeadura do híbrido de milho DKB 285 PRO de segunda safra, no espaçamento de $0,80 \mathrm{~m}$, com sete sementes por metro.

A adubação de plantio do milho foi realizada no sulco de semeadura, tendo-se utilizado $300 \mathrm{~kg} \mathrm{ha}^{-1} \mathrm{da}$ fórmula $\mathrm{N}-\mathrm{P}_{2} \mathrm{O}_{5}-\mathrm{K}_{2} \mathrm{O}$ 12-15-15. As sementes de milho foram tratadas com o produto imidacloprid+thiodicarb, na dose de $300 \mathrm{~mL}$ por $20 \mathrm{~kg}$ de sementes; também foram realizadas aplicações com inseticidas e fungicidas para o controle de pragas e doenças, respectivamente. O nitrogênio, em cobertura, foi aplicado no estádio V4 da cultura do milho, o que totalizou $40 \mathrm{~kg} \mathrm{ha}^{-1}$ de nitrogênio em cada safra de milho. Após a colheita do milho, as parcelas ficavam em pousio até a próxima safra de soja.

Tabela 1. Síntese dos tratamentos avaliados, compostos por diferentes fontes de nitrogênio, milho solteiro e consórcio de milho com Urochloa brizantha 'Marandu'.

\begin{tabular}{lcccc}
\hline $\begin{array}{l}\text { Trata- } \\
\text { mentos }\end{array}$ & Fontes de nitrogênio & $\begin{array}{c}\text { Dose } \\
\left(\mathrm{kg} \mathrm{ha}^{-1}\right)\end{array}$ & Consórcio & $\begin{array}{c}\text { Milho } \\
\text { solteiro }\end{array}$ \\
\hline 1 & Sem nitrogênio & - & - & $\mathrm{x}$ \\
2 & Sem nitrogênio & - & $\mathrm{x}$ & - \\
3 & Ureia & 89 & - & $\mathrm{x}$ \\
4 & Ureia & 89 & $\mathrm{x}$ & - \\
5 & Sulfato de amônio+ureia & $44+95$ & - & $\mathrm{x}$ \\
6 & Sulfato de amônio+ureia & $44+95$ & $\mathrm{x}$ & - \\
7 & Sulfato de amônio & 190 & - & $\mathrm{x}$ \\
8 & Sulfato de amônio & 190 & $\mathrm{x}$ & - \\
\hline
\end{tabular}

Pesq. agropec. bras., Brasília, v.51, n.12, p.2000-2009, dez. 2016 DOI: 10.1590/S0100-204X2016001200011
Após a colheita da última safra do milho em 26/9/2013, realizou-se a coleta das amostras de solo, por meio da abertura de trincheiras de $0,45 \mathrm{~m}$ de largura $\times 0,4 \mathrm{~m}$ de profundidade, nas profundidades de $0-5,5-10,10-20$ e $20-40 \mathrm{~cm}$. As amostras compostas foram encaminhadas para o laboratório de solos, onde foram secas à sombra, destorroadas e passadas em peneira de malha de $2 \mathrm{~mm}$, para determinação do carbono orgânico total (COT), lábil (CL), particulado (COP) e associado aos minerais (COM).

$\mathrm{O}$ teor de COT foi determinado de acordo com a metodologia descrita por Yeomans \& Bremner (1988). Foram pesados $0,5 \mathrm{~g}$ de terra fina seca ao ar (TFSA) passada em peneira de malha de $0,210 \mathrm{~mm}$, em tubo de destilação. Em seguida, em cada tubo, foram adicionados $5 \mathrm{~mL}$ da solução de $\mathrm{K}_{2} \mathrm{Cr}_{2} \mathrm{O}_{7} 0,167 \mathrm{~mol} \mathrm{~L}^{-1}$ e 7,5 de $\mathrm{H}_{2} \mathrm{SO}_{4}$ P.A. Os tubos foram levados ao bloco de digestão durante $30 \mathrm{~min}$ a $170^{\circ} \mathrm{C}$. Após este período, o conteúdo dos tubos foi transferido para um recipiente de $100 \mathrm{~mL}$, no qual foram colocados $50 \mathrm{~mL}$ de água destilada. A titulação de cada amostra foi realizada com solução de sulfato ferroso amoniacal, na presença de três gotas da solução indicadora de ferroína.

Para determinar o CL, foi pesado $1 \mathrm{~g}$ de TFSA passada em peneira de malha de $0,210 \mathrm{~mm}$, em tubos de centrifuga, aos quais foram adicionados $25 \mathrm{~mL}$ da solução de permanganato de potássio $0,033 \mathrm{~mol} \mathrm{~L}^{-1}$. Os tubos de centrífuga foram agitados durante 1 hora a $130 \mathrm{rpm}$, em agitador horizontal, e centrifugados a 130 rpm por 1 hora. Após este processo, pipetaram-se 100 $\mu \mathrm{L}$ do sobrenadante em tubos de ensaio e adicionaramse $10 \mathrm{~mL}$ de água destilada. O teor de CL foi, então, mensurado em espectrofotômetro, no comprimento de onda de $565 \mathrm{~nm}$, a partir da equação da curva-padrão (Shang \& Tiessen, 1997).

O fracionamento granulométrico da MOS foi realizado de acordo com Cambardella \& Elliott (1992), tendo-se obtido as frações de COP e COM. Seguindo esta metodologia, $20 \mathrm{~g}$ de TFSA foram pesados em um recipiente de $100 \mathrm{~mL}$ juntamente com $60 \mathrm{~mL}$ da solução de hexametafosfato de sódio. As amostras foram agitadas durante 15 horas em agitador horizontal. Em seguida, transferiu-se o conteúdo dos recipientes para peneira de malha de $0,053 \mathrm{~mm}$. O material retido na peneira representou o $\mathrm{COP}$, que foi seco em estufa de circulação forçada de ar a $50^{\circ} \mathrm{C}$ e moído em almofariz de porcelana, para determinar o teor de carbono de acordo 
com o método de Yeomans \& Bremner (1988). O COM foi obtido por meio da equação: $\mathrm{COM}=\mathrm{COT}$ - COP.

Os dados foram submetidos à análise de variância por meio do teste $\mathrm{F}$, a $5 \%$ de probabilidade, e, quando significativas, as médias foram comparadas pelo teste de Tukey, a 10\% de probabilidade, tendo-se utilizado o programa computacional Saeg (Universidade Federal de Viçosa, Viçosa, MG).

\section{Resultados e Discussão}

Não houve interação entre fontes de nitrogênio, profundidade do solo e tipo de cultivo para nenhum dos atributos avaliados (Tabela 2). No entanto, houve interação significativa entre fontes de nitrogênio e tipo de cultivo para COT, COP e COM, exceto para CL.

Quanto à interação entre profundidade e tipo de cultivo, verificou-se efeito significativo para COT, o que não ocorreu para os demais atributos analisados. Também houve interação significativa entre profundidade e fontes de nitrogênio para COT e COM, mas não para os demais atributos (Tabela 2).

COT, CL, COP e COM foram influenciados significativamente quando se avaliou o efeito isolado de profundidade, fonte de nitrogênio e tipo de cultivo. Para COT, ao se comparar as fontes de nitrogênio às diferentes profundidades, observou-se que $o$ tratamento com sulfato de amônio+ureia propiciou os maiores valores na profundidade de $0-5 \mathrm{~cm}$. Nas profundidades de 5-10 e 10-20 cm, o uso do sulfato de amônio+ureia e ureia proporcionou os maiores valores de COT, tendo diferido estatisticamente das demais fontes (Figura $1 \mathrm{~A}$ ).
O benefício das fontes de nitrogênio no incremento dos valores de COT está relacionado ao fato de o nitrogênio ser elemento essencial na síntese de substâncias húmicas (Stevenson, 1994). Além disso, evidências apontam que este nutriente tem importante papel na humificação e na formação de compostos orgânicos estáveis no solo (Dijkstra et al., 2004). O aumento de deposição de nitrogênio via fertilizante ou fixação biológica pode levar à redução na decomposição do húmus no solo (Michel \& Matzner, 2002) e incrementar a formação de $C$ não lábil (Hagedorn et al., 2003), o que resulta em acúmulo de MOS estabilizada (substâncias húmicas) (Lovato et al., 2004).

Em relação ao efeito da profundidade de amostragem, foram verificados maiores teores de COT na profundidade de $0-5 \mathrm{~cm}$, independentemente da fonte de nitrogênio utilizada (Figura 1 A). O maior acúmulo de carbono na superfície do solo está ligado à maior deposição de resíduos vegetais pelas plantas e ao fato de, no sistema plantio direto, o revolvimento só ocorrer na linha de semeadura, o que também contribuiu para esse aumento (Ensinas et al., 2016). De modo geral, em sistemas em que há associação de culturas com grande aporte de resíduos em plantio direto, ocorre acúmulo de grande quantidade de carbono orgânico (Lal et al., 2004). Salton et al. (2011), ao estudar o teor e a dinâmica do carbono no solo, em sistemas de integração lavoura-pecuária, também encontraram maiores teores nas camadas superficiais do solo, que decresceram com a profundidade.

Tanto o milho solteiro quanto o consórcio com $U$. brizantha 'Marandu' apresentaram efeito significativo

Tabela 2. Síntese das análises de variância para teores de carbono orgânico total (COT), lábil (CL), particulado (COP) e associado aos minerais (COM).

\begin{tabular}{|c|c|c|c|c|c|}
\hline Variáveis & GL & $\mathrm{COT}$ & $\mathrm{CL}$ & $\mathrm{COP}$ & $\mathrm{COM}$ \\
\hline Bloco & 3 & $1.87^{\mathrm{ns}}$ & $1.05^{\text {ns }}$ & $0.09^{\text {ns }}$ & $0.914^{\mathrm{ns}}$ \\
\hline Profundidade (D) & 3 & $140.066^{* *}$ & $24.166^{* *}$ & $39.577 * *$ & $7.981 * *$ \\
\hline Fonte de nitrogênio $(\mathrm{N})$ & 3 & $46.119^{* *}$ & $32.526^{* *}$ & $4.131^{* *}$ & $18.527^{* *}$ \\
\hline $\mathrm{TC}$ & 1 & $27.106^{* *}$ & $8.576^{* *}$ & $10.663^{* *}$ & $13.135^{* *}$ \\
\hline $\mathrm{DxN}$ & 9 & $4.026^{* *}$ & $0.344^{\mathrm{ns}}$ & $0.779^{\mathrm{ns}}$ & $2.089^{*}$ \\
\hline DxTC & 3 & $10.771 * *$ & $2.468^{\mathrm{ns}}$ & $0.486^{\mathrm{ns}}$ & $1.311^{\mathrm{ns}}$ \\
\hline NxTC & 3 & $11.3956^{* *}$ & $2.278^{\mathrm{ns}}$ & $5.808^{* *}$ & $7.537 * *$ \\
\hline NxDxTC & 9 & $1.4180^{\mathrm{ns}}$ & $0.789^{\text {ns }}$ & $1.143^{\text {ns }}$ & $1.564^{\mathrm{ns}}$ \\
\hline CV (\%) & & 8.38 & 19.80 & 32.12 & 23.68 \\
\hline
\end{tabular}

* e **Significativo a 5 e $1 \%$ de probabilidade, respectivamente, pelo teste $\mathrm{F} .{ }^{\text {ns }}$ Não significativo. . 
até a camada de $10 \mathrm{~cm}$ de profundidade, não tendo alterado o COT nas camadas subsuperficiais. Além disso, o cultivo do milho de segunda safra consorciado com $U$. brizantha 'Marandu' apresentou os maiores teores de COT, em comparação ao de milho solteiro (Figura 1 B). Esse resultado pode estar associado à deposição de material vegetal por Urochloa spp., principalmente na superfície do solo. Souza et al. (2009) também observaram aumento de COT em sistemas de integração com gramíneas e soja em plantio direto.

O maior aporte de COT em sistema consorciado com U. brizantha 'Marandu' se deve ao fato de culturas com sistema radicular abundante e agressivo, como as gramíneas forrageiras, alocarem maior fração do $\mathrm{C}$ fotossintetizado para as raízes do que culturas anuais (Nouvellon et al., 2012), o que as torna mais eficientes em aumentar os teores de COT no solo. Silva et al. (2011) obtiveram valores de COT, em sistema de integração lavoura pecuária com quatro e oito anos de implantação, semelhante ao de sistema plantio direto com 23 anos. Estes autores atribuíram este resultado ao maior aporte de matéria orgânica pela forrageira relacionado à menor fragmentação da matéria orgânica. Vale ressaltar que o gênero Urochloa spp. apresenta volumoso sistema radicular associado à capacidade de renovação das raízes de forma contínua e com elevado efeito de sua rizosfera (D'Andréa et al., 2004), o que contribui para o incremento de COT em sistemas de consórcio.

A interação entre fontes de nitrogênio e tipo de cultivo foi significativa. Contudo, os cultivos de milho solteiro e consorciado apresentaram resultados divergentes em relação às fontes de nitrogênio (Figura $1 \mathrm{C}$ ). Para o milho solteiro, os maiores teores de COT foram obtidos quando se utilizou sulfato de amônio+ureia, que diferiu significativamente das demais fontes. Já para o milho consorciado com $U$. brizantha 'Marandu', o uso da ureia e do sulfato de amônio+ureia promoveu os maiores valores de COT. Constatou-se que, mesmo sem aplicação de nitrogênio, o consórcio de milho com pasto resulta em maior teor de COT do que o milho solteiro (Figura $1 \mathrm{C}$ ).

Entre as fontes de nitrogênio estudadas, foi possível observar que a aplicação de ureia resultou em maior teor de COT no consórcio de milho com U. brizantha 'Marandu' (Figura $1 \mathrm{C}$ ), o que pode ser explicado pela maior eficiência na utilização do nitrogênio pela forrageira. Cabe destacar que o maior número de plantas na cobertura do solo, associado à estação do ano com menor precipitação pluvial, pode ter influenciado a redução do processo de volatilização do $\mathrm{N}-\mathrm{NH}_{3}$. Suter et al. (2016) relataram menor perda de nitrogênio por volatilização em pastagens, no período de outono/inverno do que na primavera/verão, o que atribuíram à menor umidade do solo nestas estações do ano.

Os maiores teores de CL foram verificados na camada superficial do solo, que diferiu estatisticamente das demais profundidades. Esse resultado pode ser explicado pela maior adição de resíduos pelas culturas na superfície do solo e está associado ao maior teor de COT nas camadas superficiais (Figura 1 D). Efeito similar também foi relatado por Leite et al. (2013), que encontraram teores mais elevados de CL na superfície do solo, em decorrência do aporte de resíduos.

$\mathrm{O}$ acúmulo de CL na superfície pode ter papel importante na disponibilidade de nutrientes para as espécies vegetais. Isso porque essa fração da MOS, que tem ciclagem mais rápida, é extremamente importante para a ciclagem de nutrientes, visto que é fonte de energia mais prontamente disponível para os microrganismos responsáveis por este processo (Janzen et al., 1992).

Ao se comparar os tipos de cultivo em relação ao CL, o milho de segunda safra consorciado com pasto proporcionou os maiores valores, tendo diferido estatisticamente do milho solteiro (Figura 1 E). O incremento dos valores de CL quando a Urochloa foi utilizada em consórcio com o milho pode ser atribuído ao fato de as plantas forrageiras, como as gramíneas, depositarem grandes quantidades de material orgânico; apresentarem razão $\mathrm{C} / \mathrm{N}$ e lignina/ $\mathrm{N}$ mais elevadas, além de maiores teores de lignina em comparação à hemicelulose e à celulose (Carvalho et al., 2011); serem plantas de ciclo fotossintético $\mathrm{C} 4$; e apresentarem sistema radicular que explora maiores profundidades (Moraes et al., 2008). Já ao se comparar as fontes de nitrogênio quanto ao CL (Figura $1 \mathrm{~F}$ ), a utilização do sulfato de amônio promoveu os menores teores de $\mathrm{CL}$, tendo diferido estatisticamente das demais fontes avaliadas, o que está ligado ao menor teor de COT produzido por essa fonte de nitrogênio.

O COP na profundidade de $0-5 \mathrm{~cm}$ apresentou valores altos que diferiram estatisticamente dos obtidos nas demais profundidades (Figura 2 A). Os maiores valores de COP foram observados na 

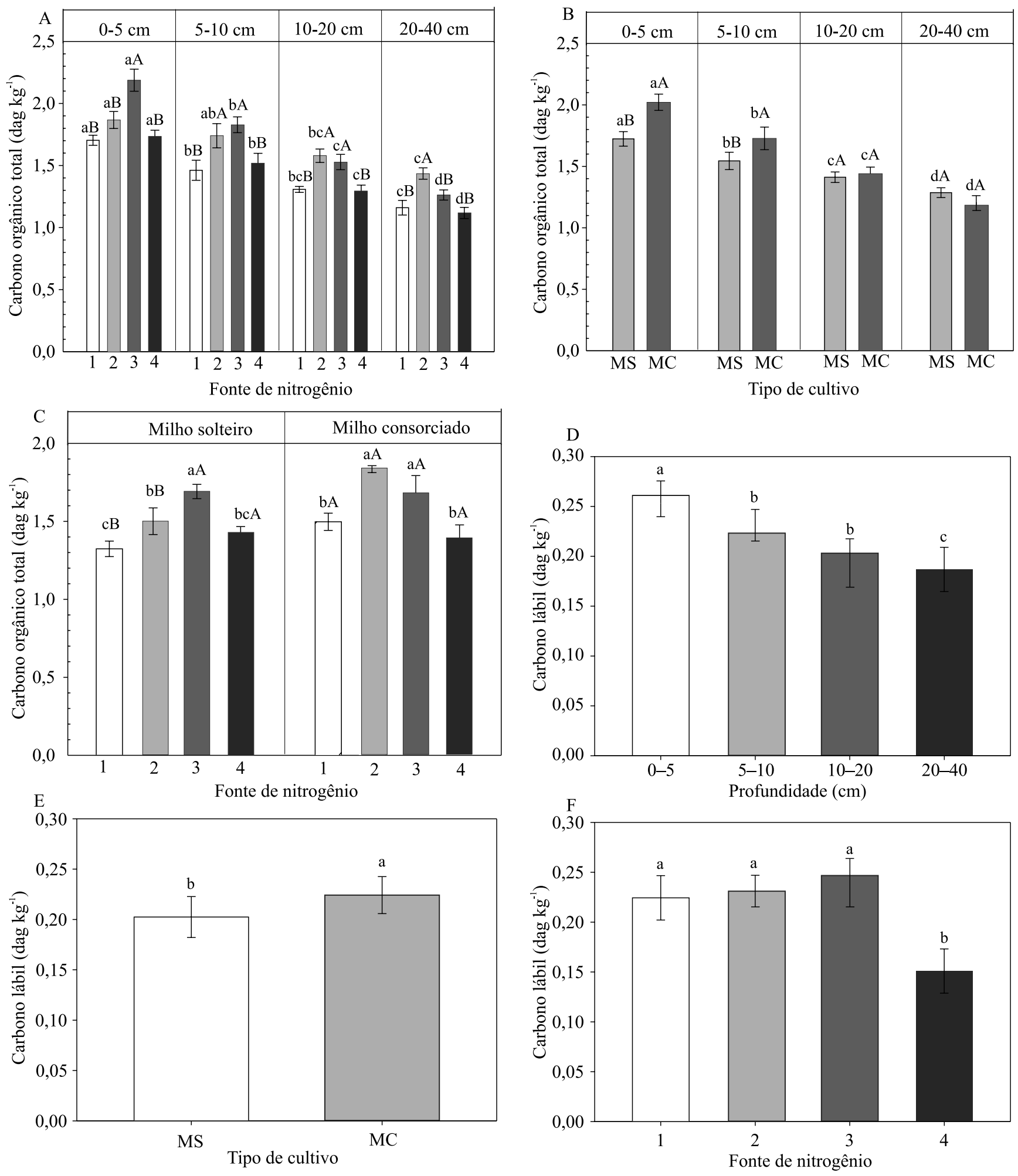

Figura 1. Teores médios de carbono orgânico total (A, B e C) e lábil (D, E e F) em função das fontes de nitrogênio: 1, sem nitrogênio; 2, ureia; 3, sulfato de amônio+ureia; e 4, sulfato de amônio, para as profundidades de 0-5, 5-10, 10-20 e 20-40 $\mathrm{cm}$ e para dois tipos de cultivo (MS, milho solteiro; e MC, milho em consórcio com Urochloa brizantha 'Marandu'). Letras iguais, maiúsculas para fonte de nitrogênio e minúsculas para profundidade, não diferem pelo teste de Tukey a $10 \%$ de probabilidade. 
profundidade de $0-5 \mathrm{~cm}$ e estão relacionados à adição de resíduos vegetais ao solo; neste caso, a matéria orgânica é oriunda das gramíneas, como milho e forrageiras, compostas por maiores relações de $\mathrm{C} / \mathrm{N}$ e lignina/ $\mathrm{N}$ total, o que infere na menor velocidade de decomposição (Costa et al., 2015). No sistema plantio direto, como há maior adição e acúmulo de resíduos vegetais na superfície do solo, também é de se esperar maiores aportes de COP na camada superficial do solo (Ensinas et al., 2016).

Os resultados obtidos no presente trabalho mostraram que a variação dos teores de COP entre as diferentes áreas estudadas, na profundidade de 0-5 cm, é dependente da adição de resíduos vegetais, em quantidade e qualidade. Assim, sistemas de uso do solo que propiciem maior adição desses resíduos na superfície do solo, com razão $\mathrm{C} / \mathrm{N}$ e lignina/ $\mathrm{N}$ favoráveis à mineralização, influenciam a manutenção dos valores de COP.

Não houve diferença significativa entre as fontes de nitrogênio quanto ao teor de COP (Figura $2 \mathrm{~B}$ ), apenas uma leve redução no teor de COP quando ureia e sulfato de amônio+ureia foram utilizados. Em relação aos tipos de cultivo, o do milho consorciado resultou em $28,2 \%$ de incremento do COP, quando comparado ao milho solteiro (Figura $2 \mathrm{C}$ ). Estudos mostraram que o gênero Urochloa tem grande potencial de fornecimento de carbono ao solo, por apresentar grande adição de resíduos vegetais e sistema radicular volumoso que é constantemente renovado (Loss et al., 2013). Ao se comparar as diferentes fontes de nitrogênio dentro de cada tipo de cultivo, notou-se que o maior teor de COP, para o milho solteiro, ocorreu na ausência de nitrogênio e, para o milho consorciado com pasto, não houve diferenças significativas entre as fontes (Figura $2 \mathrm{D}$ ).

$\mathrm{Na}$ comparação do efeito das fontes de nitrogênio em função do tipo de cultivo, houve redução do COP quando o milho solteiro foi adubado com sulfato de amônio+ureia (Figura 2 D). Com relação ao $\mathrm{COM}$, os maiores valores na profundidade de 0 $5 \mathrm{~cm}$ foram observados quando se utilizou o sulfato de amônio+ureia como fonte de nitrogênio, tendo diferido estatisticamente dos demais tratamentos (Figura 2 E). Nas profundidades de 5-10 e 10-20 cm, o sulfato de amônio+ureia também proporcionou os maiores valores, que, no entanto, não diferiram em relação ao uso isolado de ureia e sulfato de amônio.
Para a profundidade de $10-20 \mathrm{~cm}$, o COM foi maior ao se utilizar a ureia como fonte de nitrogênio, tendo diferido estatisticamente do tratamento sem nitrogênio e do com sulfato de amônio (Figura 2 E).

De maneira geral, verificou-se que a utilização de nitrogênio, em especial de sulfato de amônio+ureia, proporcionou aumento do COM, o que pode estar relacionado ao efeito do nitrogênio na formação de frações mais recalcitrantes da MOS. Para o milho solteiro, a fonte sulfato de amônio+ureia apresentou os maiores valores de COM; já para o milho consorciado com pasto, a utilização de ureia e sulfato de amônio+ureia promoveu os maiores valores, tendo diferido estatisticamente dos demais tratamentos (Figura 2 F). Os resultados obtidos no presente trabalho são indicativos de que, independentemente do sistema de cultivo, o uso de nitrogênio promove aumento de carbono em frações estáveis da MOS. Segundo Souza et al. (2009), incrementos de carbono no solo estão ligados a aumentos na disponibilidade de nitrogênio no sistema solo-planta.

Em relação aos tipos de cultivo, os maiores teores de COM foram obtidos com o milho solteiro, o que difere dos resultados apresentados anteriormente (Figura 2 G). É importante ressaltar que o sistema plantio direto, por possibilitar maior permanência do carbono no solo, proporciona efeitos positivos na manutenção do COM.

Quanto ao efeito da profundidade de amostragem, os maiores valores de COM foram obtidos nas profundidades de 5-10, 10-20 e 20-40 cm (Figura $2 \mathrm{H}$ ). De acordo com Bayer et al. (2004), o COM corresponde ao carbono orgânico associado às frações silte e argila, e apresenta avançado grau de humificação, sendo normalmente menos sensível às alterações de manejo do solo.

Os teores mais elevados de COM na subsuperfície do solo podem estar associados à maior estabilidade dos agregados nessa profundidade, o que contribui para maior estabilização da MOS. Além disso, a maior permanência do carbono nas frações mais recalcitrantes pode ser explicada pela interação dos complexos organominerais que se formam em Latossolos, o que resulta em fortes associações da matéria orgânica humificada com argilas cauliníticas e oxídicas, características desses solos. Essa associação de argilominerais no solo promove a proteção contra a decomposição da MOS por microrganismos, o que pode levar à maior estabilidade do $\mathrm{COM}$ e à sua permanência no solo (Hartman et al., 2014). 

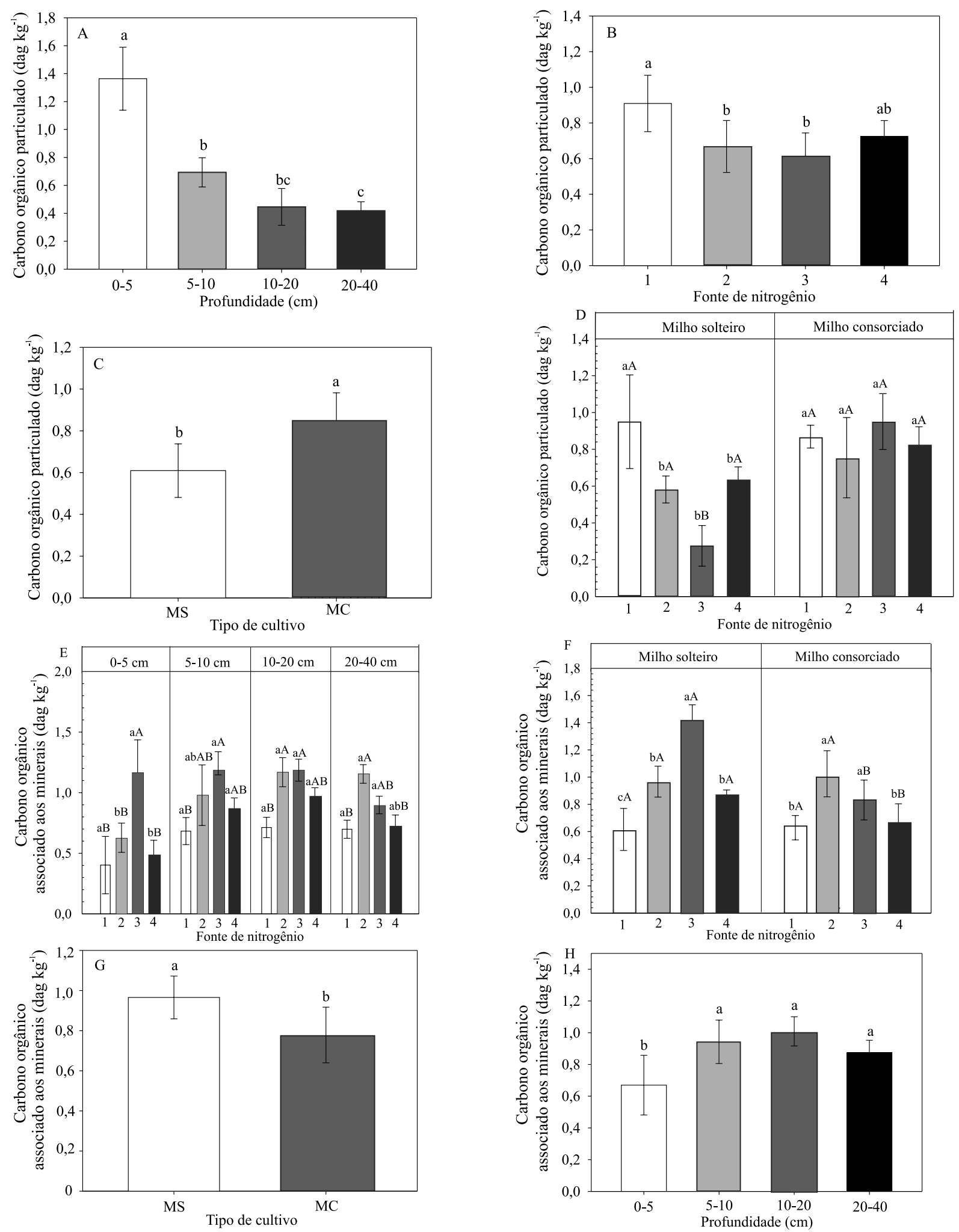

Figura 2. Teores médios de carbono orgânico particulado (A, B, C e D) e associado aos minerais (E, F, G e H) em função das fontes de nitrogênio: 1, sem nitrogênio; 2 , ureia; 3 , sulfato de amônio+ureia; e 4, sulfato de amônio, para as profundidades de 0-5, 5-10, 10-20 e 20-40 cm e para dois tipos de cultivo (MS, milho sem consórcio; e MC, milho em consórcio com Urochloa brizantha 'Marandu'. Letras iguais, maiúsculas para fonte de nitrogênio e minúsculas para profundidade, não diferem pelo teste de Tukey a $10 \%$ de probabilidade. 


\section{Conclusões}

1. O consórcio de milho (Zea mays) com Urochloa brizantha 'Marandu' resulta em maior teor de carbono orgânico total (COT), lábil (CL) e particulado (COP) do que o plantio de milho solteiro, no período outono/ inverno.

2. A ureia, como fonte de nitrogênio, aplicada no consórcio de milho com $U$. brizantha 'Marandu' proporciona incremento de COT e CL, em comparação ao uso do sulfato de amônio ou da combinação sulfato de amônio+ureia.

\section{Agradecimentos}

À Coordenação de Aperfeiçoamento de pessoal de Nível Superior (Capes), pela concessão de bolsa.

\section{Referências}

BAYER, C.; MARTIN-NETO, L.; MIELNICZUK, J.; PAVINATO, A. Armazenamento de carbono em frações lábeis da matéria orgânica de um Latossolo Vermelho sob plantio direto. Pesquisa Agropecuária Brasileira, v.39, p.677-683, 2004. DOI: 10.1590/S0100-204X2004000700009.

BORGHI, É.; CRUSCIOL, C.A.C.; NASCENTE, A.S.; MATEUS, G.P.; MARTINS, P.O.; COSTA, C. Effects of row spacing and intercrop on maize grain yield and forage production of palisade grass. Crop and Pasture Science, v.63, p.1106-1113, 2013. DOI: 10.1071/CP12344.

CAMBARDELLA, C.A.; ELLIOTT, E.T. Particulate soil organicmatter changes across a grassland cultivation sequence. Soil Science Society of America Journal, v.56, p.777-783, 1992. DOI: 10.2136/sssaj1992.03615995005600030017x.

CARVALHO, A.M. de; SOUZA, L.L.P. de; GUIMARÃES JÚNIOR, R.; ALVES, P.C.A.C.; VIVALDI, L.J. Cover plants with potential use for crop-livestock integrated systems in the Cerrado region. Pesquisa Agropecuária Brasileira, v.46, p.1200-1205, 2011. DOI: 10.1590/S0100-204X2011001000012.

CECCON, G. Milho safrinha como solo protegido e retorno econômico em Mato Grosso do Sul. Revista Plantio Direto, v.17, p.17-20, 2007.

CLAESSEN, M.E.C. (Org.). Manual de métodos de análise de solo. 2.ed. rev. e atual. Rio de Janeiro: EMBRAPA-CNPS, 1997. 212p. (EMBRAPA-CNPS. Documentos, 1).

COSTA, N.R.; ANDREOTTI, M.; ULIAN, N. de A.; COSTA, B.S.; PARIZ, C.M.; TEIXEIRA FILHO, M.C.M. Acúmulo de nutrientes e tempo de decomposição da palhada de espécies forrageiras em função de épocas de semeadura. Bioscience Journal, v.31, p.818-829, 2015. DOI: 10.14393/BJ-v31n3a2015-22434.
CRUSCIOL, C.A.C.; SORATTO, R.P.; BORGHI, E.; MATHEUS, G.P. Benefits of integrating crops and tropical pastures as systems of production. Better Crops, v.94, p.14-16, 2010.

D’ANDRÉA, A.F.; SILVA, M.L.N.; CURI, N.; GUILHERME, L.R.G. Estoque de carbono e nitrogênio e formas de nitrogênio mineral em um solo submetido a diferentes sistemas de manejo. Pesquisa Agropecuária Brasileira, v.39, p.179-186, 2004. DOI: 10.1590/S0100-204X2004000200012.

DIJKSTRA, F.A.; HOBBIE, S.E.; KNOPS, J.M.H.; REICH, P.B. Nitrogen deposition and plant species interact to influence soil carbon stabilization. Ecology Letters, v.7, p.1192-1198, 2004. DOI: 10.1111/j.1461-0248.2004.00679.x.

ENSINAS, S.C.; SERRA, A.P.; MARCHETTI, M.E.; SILVA, E.F. da; PRADO, E.A.F. do; ALTOMAR, P.H.; LOURENTE, E.R.P.; MARTINEZ, M.A.; POTRICH, D.C.; CONRAD, V. do A.; ROSA, C.B.C.J.; MATOS, F.A.; MIRANDA, R. de A.S. Impact of above-ground dry matter residue from cover crops on fall-winter corn and spring-summer soybean yield under no-tillage system. Australian Journal of Crop Science, v.9, p.1165-1172, 2015.

ENSINAS, S.C.; SERRA, A.P.; MARCHETTI, M.E.; SILVA, E.F. da; PRADO, E.A.F. do; LOURENTE, E.R.P.; ALTOMAR, P.H.; POTRICH, D.C.; MARTINEZ, M.A.; CONRAD, V. do A.; JESUS, M.V.; EL KADRI, T.C. Cover crops affect on soil organic matter fractions under no till system. Australian Journal of Crop Science, v.10, p.503-512, 2016. DOI: 10.21475/ajcs.2016.10.04. p7247x.

FREITAS, M.E.; SOUZA, L.C.F. de; SALTON, J.C.; SERRA, A.P.; MAUAD, M.; CORTEZ, J.W.; MARCHETTI, M.E. Crop rotation affects soybean performance in no-tillage system under optimal and dry cropping seasons. Australian Journal of Crop Science, v.10, p.353-361, 2016. DOI: 10.21475/ajcs.2016.10.03.p7177.

GUEDES, E.M.S.; FERNANDES, A.R.; LIMA, H.V. de; SERRA, A.P.; COSTA, J.R.; GUEDES, R. da S. Impacts of different management systems on the physical quality of an Amazonian Oxisol. Revista Brasileira de Ciência do Solo, v.36, p.1269-1277, 2012. DOI: 10.1590/S0100-06832012000400021.

HAGEDORN, F.; SPINNLER, D.; SIEGWOLF, R. Increased N deposition retards mineralization of old soil organic matter. Soil Biology \& Biochemistry, v.35, p.1683-1692, 2003. DOI: 10.1016/j. soilbio.2003.08.015.

HARTMAN, D. da C.; SÁ, J.C. de M.; BRIEDIS, C.; SANTOS, J.Z. dos; SCHIMIGUEL, R. Evidências de saturação de carbono em solos sob plantio direto em agro-ecossistemas subtropical e tropical no Brasil. Synergismus Scyentifica, v.9, p.1-6, 2014.

HU, F.; GAN, Y.; CUI, H.; ZHAO, C.; FENGA, F.; YIN, W.; CHAI, Q. Intercropping maize and wheat with conservation agriculture principles improves water harvesting and reduces carbon emissions in dry areas. European Journal of Agronomy, v.74, p.9-17, 2016. DOI: 10.1016/j.eja.2015.11.019.

JANZEN, H.H.; CAMPBELL, C.A.; BRANDT, S.A.; LAFOND, G.P.; TOWNLEY-SMITH, L. Light-fraction organic matter in soils from long-term crop rotations. Soil Science Society of America Journal, v.56, p.1799-1806, 1992. DOI: 10.2136/ sssaj1992.03615995005600060025x. 
KÖEPPEN, W. Climatología: con un estudio de los climas de la tierra. México: Fondo de Cultura Económica, 1948. 478p.

LAL, R. Soil carbon sequestration impacts on global climate change and food security. Science, v.304, p.1623-1627, 2004. DOI: 10.1126/science.1097396.

LEITE, L.F.C.; ARRUDA, F.P. de; COSTA, C. do N.; FERREIRA, J. da S.; HOLANDA NETO, M.R. Qualidade química do solo e dinâmica de carbono sob monocultivo e consórcio de macaúba e pastagem. Revista Brasileira de Engenharia Agrícola e Ambiental, v.17, p.1257-1263, 2013. DOI: 10.1590/S141543662013001200002 .

LEVANTAMENTO SISTEMÁTICO DA PRODUÇÃO AGRÍCOLA: pesquisa mensal de previsão e acompanhamento das safras agrícolas no ano civil. Rio de Janeiro: IBGE, v.29, n.1, p.1-78, 2016.

LOSS, A.; PEREIRA, M.G.; PERIN, A.; BEUTLER, S.J.; ANJOS, L.H.C. Oxidizable carbon and humic substances in rotation systems with brachiaria/livestock and pearl millet/ no livestock in the Brazilian Cerrado. Spanish Journal of Agricultural Research, v.11, p.217-231, 2013. DOI: 10.5424/ sjar/2013111-3416.

LOURENTE, E.R.P.; SILVA, E.F. da; MERCANTE, F.M.; SERRA, A.P.; PEIXOTO, P.P.P.; SEREIA, R.C.; ENSINAS, S.C.; LUIZ NETO NETO, A.L.; ALOVISI, A.M.T.; MARCHETTI, M.E.; CORTEZ, J.W. Agricultural management systems affect on physical, chemical and microbial soil properties. Australian Journal of Crop Science, v.10, p.683-692, 2016. DOI: 10.21475/ ajcs.2016.10.05.p7410.

LOVATO, T.; MIELNICZUK, J.; BAYER, C.; VEZZANI, F. Adição de carbono e nitrogênio e sua relação com os estoques no solo e com o rendimento do milho em sistemas de manejo. Revista Brasileira de Ciência do Solo, v.28, p.175-187, 2004. DOI: $10.1590 / \mathrm{S} 0100-06832004000100017$.

MICHEL, K.; MATZNER, K. Nitrogen content of forest floor Oa layers affects carbon pathways and nitrogen mineralization. Soil Biology \& Biochemistry, v.34, p.1807-1813, 2002. DOI: 10.1016/ S0038-0717(02)00170-0.

MORAES, L.F.D. de; CAMPELLO, E.F. de C.; PEREIRA, M.G.; LOSS, A. Características do solo na restauração de áreas degradadas na reserva biológica de Poço das Antas, RJ. Ciência Florestal, v.18, p.193-206, 2008. DOI: 10.5902/19805098457.

NOUVELLON, Y.; LACLAU, J.-P.; EPRON, D.; LE MAIRE, G.; BONNEFOND, J.-M.; GONÇALVES, J.L.M.; BOUILLET, J.-P. Production and carbon allocation in monocultures and mixedspecies plantations of Eucalyptus grandis and Acacia mangium in Brazil. Tree Physiology, v.32, p.680-695, 2012. DOI: 10.1093/ treephys/tps041.

POTRICH, D.C.; MARCHETTI, M.E.; POTRICH, D.C.; ENSINAS, S.C.; SERRA, A.P.; SILVA, E.F. da; SOUZA, N.H. de. Decomposição de resíduos culturais de cana-de-açúcar submetidos a diferentes doses de nitrogênio. Semina: Ciências Agrárias, v.35, p.1751-1760, 2014. DOI: 10.5433/1679-0359.2014v35n4p1751.
ROSA, C.B.C.J.; MARCHETTI, M.E.; SERRA, A.P.; ROSA, M.S.M.; ENSINAS, S.C.; CONRAD, V. do A.; ALTOMAR, P.H.; POTRICH, D.C.; MARTINEZ, M.A. Short-term effects of lime management in soybean no-tillage system implementation in Brazilian savannah. Australian Journal of Crop Science, v.9, p.232-241, 2015.

SALTON, J.C.; MIELNICZUK, J.; BAYER, C.; FABRÍCIO, A.C.; MACEDO, M.C.M.; BROCH, D.L. Teor e dinâmica do carbono no solo em sistemas de integração lavoura-pecuária. Pesquisa Agropecuária Brasileira, v.46, p.1349-1356, 2011. DOI: 10.1590/ S0100-204X2011001000031.

SANTOS, H.G. dos; JACOMINE, P.K.T.; ANJOS, L.H.C. dos; OLIVEIRA, V.A. de; LUBRERAS, J.F.; COELHO, M.R.; ALMEIDA, J.A. de; CUNHA, T.J.F.; OLIVEIRA, J.B. de. Sistema brasileiro de classificação de solos. 3.ed. rev. e ampl. Brasília: Embrapa, 2013. 353p.

SHANG, C.; TIESSEN, H. Organic matter lability in tropical Oxisol: evidence from shifting cultivation, chemical oxidation, particle size, density, and magnetic fractionations. Soil Science, v.162, p.795-807, 1997. DOI: 10.1097/00010694-199711000-00004.

SILVA, E.F. da; LOURENTE, E.P.R.; MARCHETTI, M.E.; MERCANTE, F.M.; FERREIRA, A.K.T.; FUJII, G.C. Frações lábeis e recalcitrantes da matéria orgânica em solos sob integração lavoura-pecuária. Pesquisa Agropecuária Brasileira, v.46, p.1321-1331, 2011. DOI: 10.1590/S0100-204X2011001000028.

SIQUEIRA NETO, M.; PICCOLO, M. de C.; SCOPEL, E.; COSTA JÚNIOR, C. da; CERRI, C.C.; BERNOUX, M. Carbono total e atributos químicos com diferentes usos do solo no Cerrado. Acta Scientiarum. Agronomy, v.31, p.709-717, 2009. DOI: 10.4025/actasciagron.v31i4.792.

SOUZA, E.D. de; COSTA, S.E.V.G. de A.; ANGHINONI, I.; CARVALHO, P.C. de F.; ANDRIGUETI, M.; CAO, E. Estoques de carbono orgânico e de nitrogênio no solo em sistema de integração lavoura-pecuária em plantio direto, submetido a intensidades de pastejo. Revista Brasileira de Ciência do Solo, v.33, p.18291836, 2009. DOI: 10.1590/S0100-06832009000600031.

SOUZA, L.C.F. de; FREITAS, M.E.; LOURENTE, E.R.P.; SERRA, A.P.; RECH, J.; FROTA, F.; LOUREIRO, G.E.S. The effects of crop rotation systems on maize agronomic traits under no-tillage in optimal and dry cropping seasons. African Journal of Agricultural Research, v.11, p.2369-2377, 2016. DOI: 10.5897/ AJAR2016.11179.

STEVENSON, F.J. Humus chemistry: genesis, composition and reactions. $2^{\text {nd }}$ ed. New York: J. Willey \& Sons, 1994. 496p.

SUTER, H.C.; SULTANA, H.; DAVIES, R.; WALKER, C.; CHEN, D. Influence of enhanced efficiency fertilisation techniques on nitrous oxide emissions and productivity response from urea in a temperate Australian ryegrass pasture. Soil Research, v.54, p.523-532, 2016. DOI: $10.1071 / \mathrm{sr} 15317$.

YEOMANS, J.C.; BREMNER, J.M. A rapid and precise method for routine determination of organic carbon in soil. Communications in Soil Science and Plant Analysis, v.19, p.1467-1476, 1988. DOI: 10.1080/00103628809368027.

Recebido em 8 de abril de 2016 e aprovado em 11 de julho de 2016 